\title{
Accuracy and precision guidelines for optimal breeding time in bitches using in-house progesterone measurement compared with chemiluminescent microparticle immunoassay
}

\author{
Nutnaree Kunanusont ${ }^{1}$ (D), Darsaniya Punyadarsaniya² ${ }^{2}$ and Sakchai Ruenphet ${ }^{2}$ (i)
}

1. Clinic for Horse, Faculty of Veterinary Medicine, Mahanakorn University of Technology, Bangkok, Thailand; 2. Department of Immunology and Virology, Veterinary Medicine Faculty, Mahanakorn University of Technology, Bangkok, Thailand.

Corresponding author: Sakchai Ruenphet, e-mail: rsakchai@hotmail.com

Co-authors: NK: dr.pukpuipony@gmail.com, DP: darsaniya_p@yahoo.de

Received: 08-10-2020, Accepted: 27-01-2021, Published online: 08-03-2021

doi: www.doi.org/10.14202/vetworld.2021.585-588 How to cite this article: Kunanusont N, Punyadarsaniya D, Ruenphet S (2021) Accuracy and precision guidelines for optimal breeding time in bitches using in-house progesterone measurement compared with chemiluminescent microparticle immunoassay, Veterinary World, 14(3): 585-588.

\begin{abstract}
Background and Aim: The concentration of serum progesterone is commonly used to determine the optimal mating time in bitches, and to diagnose reproductive-related abnormalities. This study aims to compare the serum progesterone results obtained by rapid fluorescence immunochromatography assay (RFICA) with those obtained by chemiluminescent microparticle immunoassay (CMIA) from the same serum samples to develop a standard guideline for optimal breeding time.

Materials and Methods: Serum progesterone levels were measured in 124 bitches using RFICA and CMIA. Simple linear regression and correlation analyses were performed to analyze the data. The percentage difference between the maximum and minimum progesterone values in the same serum sample in the same assay was compared using Wilcoxon's rank-sum test.

Results: The present study showed a strong linear dependence of the results obtained by RFICA on those obtained by CMIA as $\mathrm{R}^{2}=0.8976$, with regression coefficient of 0.9474 and $\mathrm{p}<0.05$, including the regression model was $\mathrm{CMIA}=(0.9483$ $\times$ RFICA) -0.761 . Moreover, five critical measurement times during estrous in bitches showed statistically significant differences $(\mathrm{p}<0.05)$, except at the fertilizable period, which showed a non-significant difference $(\mathrm{p}>0.05)$.

Conclusion: This study demonstrated that it is presumably acceptable to use the RFICA and CMIA methods interchangeably for quality progesterone measurements in serum samples from bitches. However, when considering the use of the RFICA method, it is advisable to carefully interpret the results and follow the interpretation guidelines. Finally, RFICA in the present study provides a reliable and convenient option for veterinarian practitioners to measure canine progesterone levels in-house.
\end{abstract}

Keywords: bitches, chemiluminescent microparticle immunoassay, optimal breed timing, progesterone, rapid fluorescence immunochromatography assay.

\section{Introduction}

The concentration of serum progesterone is commonly used to determine the optimal mating time in bitches [1-3], including the assessment of reproductive abnormalities such as ovarian dysfunction during pregnancy (e.g., hypoluteoidism) [4,5] and estrous cycle manipulation, especially verification of luteolysis before parturition [6]. Edens [7] and Olson et al. [8] reported serum progesterone concentrations of the estrous cycle as (1) above basal concentration at $>1 \mathrm{ng} / \mathrm{mL}$, indicating proestrus stage; (2) $2.0 \mathrm{ng} / \mathrm{mL}$ indicating the day of the luteinizing hormone (LH) surge; (3) $4-10 \mathrm{ng} / \mathrm{mL}$ on the ovulation day; and (4) $>5 \mathrm{ng} / \mathrm{mL}$ indicating post-ovulation.

Several qualitative, quantitative, and semi-quantitative methods for progesterone measurements are

Copyright: Kunanuson, et al. Open Access. This article is distributed under the terms of the Creative Commons Attribution 4.0 International License (http://creativecommons.org/licenses/ by/4.0/), which permits unrestricted use, distribution, and reproduction in any medium, provided you give appropriate credit to the original author(s) and the source, provide a link to the Creative Commons license, and indicate if changes were made. The Creative Commons Public Domain Dedication waiver (http:// creativecommons.org/publicdomain/zero/1.0/) applies to the data made available in this article, unless otherwise stated. available for veterinarian practitioners. In general, quantitative assays are preferred, such as radioimmunoassay (RIA) $[9,10]$, liquid chromatography-tandem mass spectrometry [11-13], the more recently introduced enzyme-linked fluorescence assay, and chemiluminescence immunoassay (CLIA) [10,14-16].

However, serum progesterone measurement results show variations due to different laboratory methods and bitches. Therefore, accurate determination of optimal breeding time requires collection of several serial blood samples during proestrus and estrous stages to compare against the gold standard or reference laboratory methods. Thus, in this study, serum progesterone results obtained by rapid fluorescence immunochromatography assay (RFICA) were compared with those obtained by chemiluminescent microparticle immunoassay (CMIA) for the same serum samples to determine a standard guideline for optimal breeding time.

\section{Materials and Methods}

\section{Ethical approval and Informed consent}

Guidelines used for the care and use of animals were approved by the Animal Research 
Ethics Committee, Faculty of Veterinary Medicine, Mahanakorn University of Technology, Thailand, approval number ACUC-MUT-2020/006. A consent form was signed by the bitch owners to participate in the study.

\section{Study period and location}

Blood samples were collected from August 2019 to July 2020 at the Small Animal Teaching Hospital, Faculty of Veterinary Medicine, Mahanakorn University of Technology, Thailand, and Vet Home Polyclinic, Bangkok, Thailand.

\section{Sample collection}

One-hundred and twenty-four bitches of different breeds such as the American bullies, English bulldog, French bulldog, Chihuahuas, Pomeranian, Chow Chow, Akita, and Pug were hospitalized for routine estrous observation and artificial insemination at the Small Animal Teaching Hospital, Faculty of Veterinary Medicine, Mahanakorn University of Technology, Thailand, and Vet Home Polyclinic, Bangkok, Thailand. Blood samples were collected from all the bitches by performing venipuncture 5-7 days after the onset of vaginal swelling or discharge. Blood was allowed to clot and then centrifuged at $3000 \mathrm{~g}$ for $7 \mathrm{~min}$. The harvested sera were transferred into microtubes and stored at $30^{\circ} \mathrm{C}$ until required for testing.

\section{Progesterone measurements}

The concentration of progesterone in each serum sample was determined by (1) RFICA using a Dianotech Fluorescence Quantitative Analyzer and canine progesterone rapid test kit (Beijing Dianotech Science and Technology Co., Ltd., Beijing, China) and (2) by CMIA using an Architect i2000SR Immunoassay Analyzer and Reagent Architect Progesterone (Abbott Laboratories, Illinois, USA).

\section{Statistical analysis}

Statistical methods involved simple linear regression and correlation analyses to determine the relationship between the RFICA and CMI. A correlation coefficient of $\leq 0.35$ was defined as low or weak correlation, 0.36-0.67 as moderate correlation, 0.680.89 as high correlation, and $>0.90$ as very high correlation [17]. The square root of RFICA was regressed on the square root of CMIA. Squaring both sides of the derived regression equation provided a formula for predicting RFICA from CMIA. Data analysis was performed using Stata 14 (Stata Corp, College Station, TX, USA) and Excel.

Percentage differences between maximum and minimum progesterone values on the same serum sample in the same assay were compared using the Wilcoxon's rank-sum test.

\section{Results}

Figure-1 shows a strong linear dependence of the results obtained by RFICA on those obtained by CMIA as $\mathrm{R}^{2}=0.8976$, with regression coefficient of 0.9474 and $p<0.05$. The regression model was $\mathrm{CMIA}=(0.9483 \times$ RFICA $)-0.761$.

The ratio of the standard deviation to the mean, namely, the coefficient of variation, for critical times during estrus in bitches such as stages of anestrus; namely, proestrus or pre-LH surge, LH surge, post-LH surge and pre-ovulation, at or near ovulation day, and fertilizable period, was $71.12 \%, 8.54 \%, 7.24 \%$, $38.89 \%$, and $25.56 \%$ for CMIA and $38.46 \%, 8.46 \%$, $6.93 \%, 28.18 \%$, and $46.87 \%$ for RFICA, respectively.

The results of progesterone levels obtained using RFICA were higher than those obtained using CMIA. On the day that CMIA showed stages of anestrus, proestrus or pre-LH surge, RFICA measured higher than CMIA in 44 of 44 bitches sera $(100 \%, \mathrm{p}<0.001)$, similar to the stage of LH surge (19 of 20;95\%, $\mathrm{p}<0.001$ ), post-LH surge and pre-ovulation ( 8 of 8 ; $100 \%, \mathrm{p}=0.016$ ), and at or near ovulation day ( 22 of $36 ; 61.11 \%, p=0.026$ ). However, during the fertilizable period, the progesterone level shown by RFICA was lower than that shown by CMIA in 10 of 16 bitch sera $(62.50 \%, \mathrm{p}=0.565)($ Table-1).

\section{Discussion}

The quantitative and objective measurements of progesterone levels are essential for assessing the reproductive status in bitch, especially optimal breeding time, and predicting or monitoring parturition. RIA has long been used as the gold standard method to measure the value of progesterone in bitches [18-21]; however, in 2014, the CLIA method was accepted and became popular for progesterone measurement [22-24]. CMIA is a modified and advanced form of CLIA and used by veterinary reference laboratories in Thailand. Limitations of both CLIA and CMIA were that they take several hours to several days for processing, depending on the location of the laboratory. However, in-house progesterone measurement is trending as a tool for veterinarian practitioners because it is simple, convenient, and rapid.

The present study showed a good correlation of progesterone measurement in the same serum sample for both RFICA and CMIA assays. These results indicated that in-house progesterone measurement using RFICA demonstrated a high correlation to the veterinary reference laboratory using CMIA. Five critical measurement times during estrous in bitches showed statistically significant differences, except at the fertilizable period, which showed a non-significant difference, indicating no difference between both measurement assays. The precision of progesterone measurement must be calculated using the equation of linear regression. However, in the fertilizable period, there is no need to calculate the precision of progesterone measurement using RFICA because at this level, there was no difference using both measurement assays.

Based on these results, it was concluded that using RFICA instead of CMIA to determine the concentration of progesterone in bitch sera required a change in 


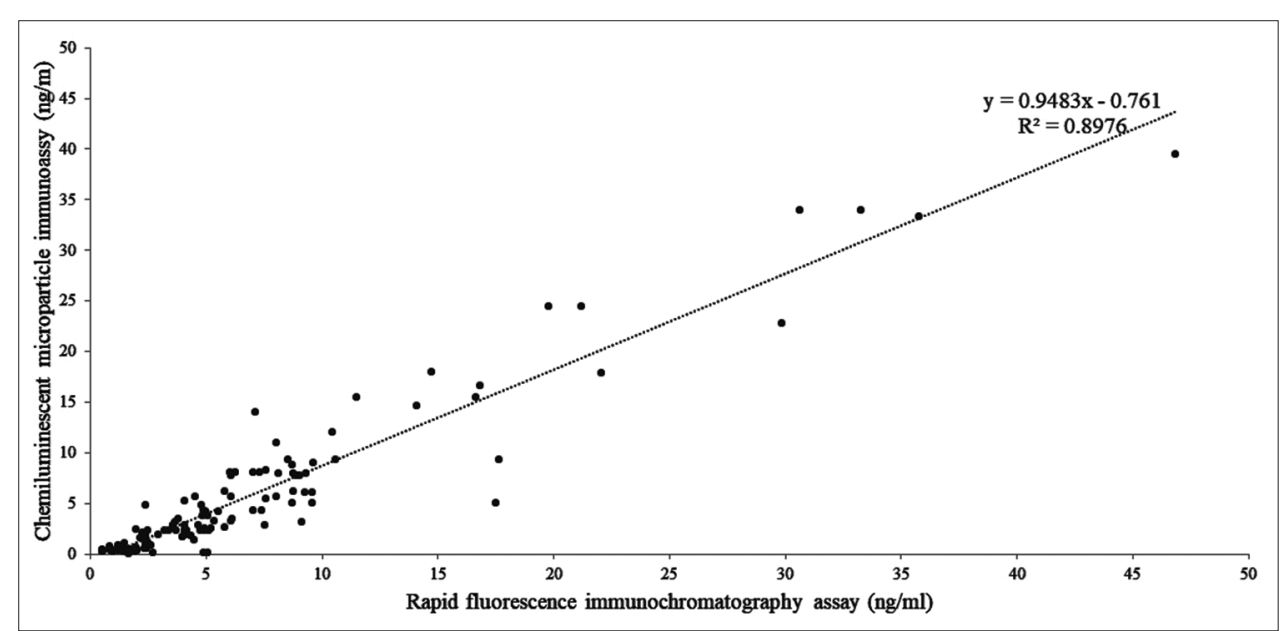

Figure-1: Correlation graph of progesterone measurement between rapid fluorescence immunochromatography assays compared with chemiluminescent microparticle immunoassay.

Table-1: Concentrations of progesterone measured with RFICA and CMIA and critical times during estrus in bitches.

\begin{tabular}{|c|c|c|c|c|c|c|c|c|c|}
\hline $\begin{array}{l}\text { Stage of } \\
\text { estrous cycle }\end{array}$ & Minimum & $25^{\text {th }}$ percentile & Median & $75^{\text {th }}$ percentile & Maximum & Mean & SD & $\mathbf{n}$ & $\mathbf{p}$ \\
\hline \multicolumn{10}{|c|}{ Anestrus, proestrus, and pre-LH surge (below $2.00 \mathrm{ng} / \mathrm{mL}$ ) } \\
\hline CMIA & 0.1 & 0.40 & 0.58 & 1.37 & 1.97 & 0.83 & 0.58 & 44 & \multirow[t]{2}{*}{$<0.001$} \\
\hline RFICA & 0.5 & 1.28 & 1.97 & 2.46 & 5.04 & 2.14 & 1.17 & 44 & \\
\hline \multicolumn{10}{|c|}{ LH surge $(2.00-2.99 \mathrm{ng} / \mathrm{mL})$} \\
\hline CMIA & 2.21 & 2.35 & 2.40 & 2.66 & 2.89 & 2.51 & 0.21 & 20 & \multirow[t]{2}{*}{$<0.001$} \\
\hline RFICA & 1.95 & 3.43 & 4.07 & 4.91 & 7.51 & 4.16 & 1.25 & 20 & \\
\hline \multicolumn{10}{|c|}{ Post-LH surge and pre-ovulation $(3.00-3.99 \mathrm{ng} / \mathrm{mL})$} \\
\hline CMIA & 3.16 & 3.26 & 3.45 & 3.75 & 3.82 & 3.47 & 0.24 & 8 & \multirow[t]{2}{*}{0.016} \\
\hline RFICA & 3.66 & 4.05 & 5.20 & 6.09 & 9.13 & 5.49 & 1.62 & 8 & \\
\hline \multicolumn{10}{|c|}{ At or near ovulation $(4.00-10.00 \mathrm{ng} / \mathrm{mL})$} \\
\hline CMIA & 4.2 & 5.07 & 6.21 & 8.07 & 9.40 & 6.70 & 1.69 & 36 & \multirow[t]{2}{*}{0.026} \\
\hline RFICA & 2.37 & 6.03 & 7.58 & 9.01 & 17.64 & 7.83 & 3.00 & 36 & \\
\hline \multicolumn{10}{|c|}{ In fertilizable period $(10.01-40.00 \mathrm{ng} / \mathrm{mL})$} \\
\hline CMIA & 11.05 & 14.88 & 18.00 & 31.15 & 39.52 & 21.77 & 8.73 & 16 & \multirow[t]{2}{*}{$0.565^{*}$} \\
\hline RFICA & 7.09 & 12.15 & 18.28 & 30.44 & 46.81 & 21.16 & 10.88 & 16 & \\
\hline
\end{tabular}

*Non-significant difference ( $p>0.05)$. RFICA=Rapid fluorescence immunochromatography assay,

CMIA=Chemiluminescent microparticle immunoassay, LH=Luteinizing hormone

Table-2: Reference or guideline for progesterone interpretation using RFICA in heat or apparent reproductively quiescent bitches.

\begin{tabular}{|c|c|c|}
\hline $\begin{array}{l}\text { Progesterone } \\
(\mathrm{ng} / \mathrm{mL})\end{array}$ & Likely events & Action \\
\hline$<2$ & $\begin{array}{l}\text { Anestrus, } \\
\text { proestrus, and } \\
\text { pre-LH surge }\end{array}$ & Retest in $2-3$ days \\
\hline $2-3$ & LH surge & $\begin{array}{l}\text { Retest in } 2 \text { days to } \\
\text { confirm continued rise in } \\
\text { progesterone. (aim for } \\
\text { breeding } 4-7 \text { days) }\end{array}$ \\
\hline $3-4$ & $\begin{array}{l}\text { Post-LH } \\
\text { surge and } \\
\text { pre-ovulation }\end{array}$ & $\begin{array}{l}\text { Retest in } 1-2 \text { days to } \\
\text { confirm continued rise in } \\
\text { progesterone. (aim for } \\
\text { breeding } 3-5 \text { days) }\end{array}$ \\
\hline $4-10$ & $\begin{array}{l}\text { At or near } \\
\text { ovulation }\end{array}$ & $\begin{array}{l}\text { Retest in } 1 \text { day to } \\
\text { confirm continued rise in } \\
\text { progesterone. (aim for } \\
\text { breeding } 2-4 \text { days) }\end{array}$ \\
\hline $10-40$ & $\begin{array}{l}\text { In fertilizable } \\
\text { period }\end{array}$ & $\begin{array}{l}\text { Aim for breeding on } \\
\text { this day and for another } \\
2-3 \text { days hereafter. }\end{array}$ \\
\hline
\end{tabular}

RFICA: Rapid fluorescence immunochromatography assay, $\mathrm{LH}=$ Luteinizing hormone the target concentrations associated with critical events during estrus as well as a change in the interpretation of the temporal relationship between reaching the respective target concentration with both assays. Therefore, RFICA was made the reference or guideline for optimal breeding time interpretation (Table-2).

\section{Conclusion}

The present study demonstrated that it is presumably acceptable to use the RFICA and CMIA methods interchangeably for quality progesterone measurements in serum samples from bitches. However, when considering the use of the RFICA method, it is advisable to interpret the results carefullyand follow the interpretation guidelines as per Table-2. Finally, RFICA in the present study provides a reliable and convenient option for veterinarian practitioners to measure canine progesterone in-house.

\section{Authors' Contributions}

NK, DP, and SR carried out the main research works and analyzed the main data in the experiments. SR 
supervised the laboratory work and approved the final version of the manuscript. All authors have read and approved the final manuscript.

\section{Acknowledgments}

The present study was supported in part by a grant from Mahanakorn University of Technology (Thailand), Vetanymall (Thailand), and Beijing Dianotech Science and Technology (China), for funding this research through Veterinary Research Grant with Contract No. Immuno-002-2020. Finally, the authors are thankful to Bangkok R.I.A. Co., Ltd. (Thailand) for CMIA supporting.

\section{Competing Interests} interests.

The authors declare that they have no competing

\section{Publisher's Note}

Veterinary World remains neutral with regard to jurisdictional claims in published institutional affiliation.

\section{References}

1. Concannon, P.W. (2011) Reproductive cycles of the domestic bitch. Anim. Reprod. Sci., 124(3-4): 200-210.

2. Gropetti, D., Aralla, M., Bronzo, V., Bosi, G., Pecile, A. and Arrighi, S. (2015) Periovulatory time in the bitch: What's new to know? Comparison between ovarian histology and clinical features. Anim. Reprod. Sci., 152: 108-116.

3. Rota, A., Vannozzi, I., Marianelli, S., Gavazza, A. and Lubas, G. (2016) Laboratory and clinical evaluation of a FEIA method for canine serum progesterone assay. Reprod. Domest. Anim., 51(1): 69-74.

4. Tibold, A. and Thuroczy, J. (2009) Progesterone, oestradiol, FSH and LH concentrations in serum of progesterone-treated pregnant bitches with suspected luteal insufficiency. Reprod. Domest. Anim., 44(2): 129-132.

5. Johnson, C.A. (2008) High-risk pregnancy and hypoluteoidism in the bitch. Theriogenology, 70(9): 1424-1430.

6. Laiblin, C. (1991) Estrus detection in the bitch with a progesterone rapid test (EIA)-a sensible supplement to vaginal cytology. Tierarztl. Prax., 19(2): 197-199.

7. Edens, M.S.D. and Heath, A.M. (2003) Breeding management in the bitch and queen. In: Small Animal Theriogenology. Ch. 2. Butterworth-Heinemann, Saint Louis. p33-60.

8. Olson, P.N., Bowen, R.A., Behrendt, M.D., Olson, J.D. and Nett, T.M. (1982) Concentrations of reproductive hormones in canine serum throughout late anestrus, proestrus and estrus. Biol. Reprod., 27(5): 1196-1206.

9. Skenandore, C.S., Pineda, A., Bahr, J.M., NewellFugate, A.E. and Cardoso, F.C. (2017) Evaluation of a commercially available radioimmunoassay and enzyme immunoassay for the analysis of progesterone and estradiol and the comparison of two extraction efficiency methods. Domest. Anim. Endocrinol., 60: 61-66.

10. Tal, S., Mazaki-Tovi, M., Druker, S., Novak, S., Raz, T. and Aroch, I. (2020) Evaluation of two chemiluminescent assays compared with radioimmunoassay for serum progesterone measurement in bitches. Theriogenology, 147: 116-123.

11. Trabert, B., Falk, R.T., Stanczyk, F.Z., McGlynn, K.A., Brinton, L.A. and Xu, X. (2015) Reproducibility of an assay to measure serum progesterone metabolites that may be related to breast cancer risk using liquid chromatography-tandem mass spectrometry. Horm. Mol. Biol. Clin. Investig., 23(3): 79-84.

12. Patton, P.E., Lim, J.Y., Hickok, L.R., Kettel, L.M., Larson, J.M. and Pau, K.Y. (2014) Precision of progesterone measurements with the use of automated immunoassay analyzers and the impact on clinical decisions for in vitro fertilization. Fertil. Steril., 101(6): 1629-1636.

13. Sasaki, M., Ochiai, H., Takahashi, K., Suzuki, R., Minato, K. and Fujikata, A. (2015) Development and validation of LC-MS/MS assay for the quantification of progesterone in rat plasma and its application to pharmacokinetic studies. Drug Res. (Stuttg.), 65(9): 484-489.

14. Moxon, R., Copley, D. and England, G.C. (2010) Technical and financial evaluation of assays for progesterone in canine practice in the UK. Vet. Rec., 167: 528-531.

15. Nöthling, J.O., de Cramer, K.G.M. (2018) Comparing the values of progesterone in the blood of bitches as measured with a chemiluminescence immunoassay and a radioimmunoassay. Reprod. Domest. Anim., 53(5): 1136-1141.

16. Lee, S., Zhao, M., No, J., Nam, Y., Im, G.S. and Hur, T.Y. (2017) Dog cloning with in vivo matured oocytes obtained using electric chemiluminescence immunoassay-predicted ovulation method. PLoS One, 12(3): e0173735.

17. Taylor, R. (1990) Interpretation of the correlation coefficient: A basic review. J. Diagn. Med. Sonogr., 6(1): 35-39.

18. Kutzler, M.A., Mohammed, H.O., Lamb, S.V. and MeyersWallen, V.N. (2003) Accuracy of canine parturition date prediction from the initial rise in preovulatory progesterone concentration. Theriogenology, 60(6): 1187-1196.

19. Luz, M.R., Bertan, C.M., Binelli, M. and Lopes, M.D. (2006) Plasma concentrations of 13, 14-dihydro-15-keto prostaglandin F2-alpha (PGFM), progesterone and estradiol in pregnant and nonpregnant diestrus cross-bred bitches. Theriogenology, 66(6-7): 1436-1441.

20. Okkens, A.C., Teunissen, J.M., van Osch, W., van den Brom, W.E., Dieleman, S.J. and Kooistra, H.S. (2001) Influence of litter size and breed on the duration of gestaton in dogs. J. Reprod. Fertil. Suppl., 57: 193-197.

21. Steckler, D., Nöthling, J.O. and Harper, C. (2013) Prediction of the optimal time for insemination using frozen-thawed semen in a multi-sire insemination trial in bitches. Anim. Reprod. Sci., 142(3-4): 191-197.

22. Rota, A., Charles, C., Cucuzza, A.S. and Pregel, P. (2015) Diagnostic efficiency of a single progesterone determination to assess full-term pregnancy in the bitch. Reprod. Domest. Anim., 50(6): 1028-1031.

23. Schmicke, M., Urhausen, C., Wolf, K., Schmidt, S. and Günzel-Apel, A.R. (2016) Evaluation of the blood progesterone concentration in the bitch measured by chemiluminescence immunoassay at the day of ovulation. Tierarztl. Prax. Ausg. K Kleintiere Heimtiere, 44(5): 317-322.

24. Volkmann, D.H. (2006) The effects of storage time and temperature on coagulation laboratory measurements of canine blood progesterone concentrations. Theriogenology, 66(6-7): 1583-1586. 